\title{
Anxiety, Distress, and Turnover Intention of Healthcare Workers in Peru by Their Distance to the Epicenter during the COVID-19 Crisis
}

\author{
Jaime A. Yáñez, ${ }^{1,2 \star}$ Asghar Afshar Jahanshahi, ${ }^{3}$ Aldo Alvarez-Risco, ${ }^{4}$ Jizhen Li, ${ }^{5}$ and Stephen X. Zhang ${ }^{6}$ \\ ${ }^{1}$ Carrera de Educacion y Gestion del Aprendizaje, Facultad de Educacion, Universidad Peruana de Ciencias Aplicadas, Lima, Peru; ${ }^{2}$ Teoma Global, \\ Gerencia Corporativa de Asuntos Científicos y Regulatorios, Lima, Peru; ${ }^{3}$ CENTRUM Católica Graduate Business School (CCGBS), Pontificia \\ Universidad Católica Del Peru (PUCP), Lima, Peru; ${ }^{4}$ Carrera de Negocios Internacionales, Facultad de Ciencias Empresariales y Economicas, \\ Universidad de Lima, Lima, Peru; ${ }^{5}$ Tsinghua University, Beijing, China; ${ }^{6}$ University of Adelaide, Adelaide, Australia
}

\begin{abstract}
We conducted a cross-sectional survey to assess the anxiety, distress, and turnover intention (likelihood to leave their current job) of healthcare workers in Peru during the COVID-19 pandemic. Our results reported that $21.7 \%$ healthcare workers in Peru experienced severe anxiety, whereas $26.1 \%$ of them experienced severe mental distress. A higher level of education related with a lower level of anxiety. Younger workers had a higher level of turnover intention than their older colleagues did. Healthcare workers in the private sector had a higher turnover intention than those in the public sector. Most importantly, people who were geographically far from Lima, the epicenter in Peru, during the outbreak experienced less anxiety and mental distress, corroborating the ripple effect and disconfirming the typhoon eye theory. However, the direction of these relationships can change depending on the type of institutions (public versus private) and the type of employees' contract (full time versus part time). Our research helps provide insights for clinical professionals in identifying the vulnerable groups to mental disorders in Peru. This is the first study to assess anxiety, mental distress, and turnover intention in healthcare workers in Peru during the COVID-19 pandemic.
\end{abstract}

\section{INTRODUCTION}

Peru has enabled the most restrictive measures in its national public health history to control the current COVID-19 outbreak. $^{1-4}$ The first patient with COVID-19 in Peru was detected in Lima on March $5,2020 .^{5}$ Five days after, classes in schools were suspended nationwide, and on March 12, all classes at universities were suspended nationally. ${ }^{6}$ On March 15 , a state of emergency, border closure, and lockdown was declared with the order of social isolation for 15 days, ${ }^{7}$ which has been extended multiple times, and currently, it has been announced to be until June 30, 2020. Those measures were very similar to the ones imposed in China, which have affected people's lives, jobs, health, and well-being, ${ }^{8}$ increasing stress and anxiety ${ }^{9,10}$ during the COVID-19 outbreak.

Because of the social isolation in Peru, the COVID-19 crisis is expected to affect people's mental health, especially that of healthcare workers. After the first case was detected on March 5,2020 , the confirmed cases increased rapidly overwhelming healthcare workers. Furthermore, personal protection equipment (PPE) access, burnout due to long work hours, not seeing their families for many days, the high risk of becoming infected, and the psychological harm of uncertainty have been reported to affect the physical and psychological status of healthcare workers in China ${ }^{11}$ and Iran. ${ }^{11,12}$ However, at the best of our knowledge, this has not been properly studied in Peru, as it has already been reported in China, ${ }^{13-15}$ Singapore, ${ }^{16}$ Iran, ${ }^{12,17}$ Italy, ${ }^{18,19}$ France, ${ }^{20}$ United Kingdom, ${ }^{21}$ and Spain. ${ }^{22,23}$ The COVID-19 crisis is causing an increase in burnout or anxiety, ${ }^{24,25}$ which resulted in an unprecedented psychological impact, ${ }^{26-28}$ and affecting people's life satisfaction that is one of the most critical indicators of mental health. ${ }^{29,30}$ We aim to use early evidence in Peru to help mental

*Address correspondence to Jaime A. Yáñez, Facultad de Educación, Carrera de Educación y Gestion del Aprendizaje, Universidad Peruana de Ciencias Aplicadas, Avenida Prolongación Primavera 2390, Los Alamos de Monterrico, Santiago de Surco, Lima 15023, Peru. E-mail: jaimeayanez@gmail.com health service provide in screening people with psychological issues during the COVID-19 outbreak from a novel perspective of typhoon eye theory. ${ }^{13,31-33}$ It has been observed that people who reside far from the epicenter of an outbreak usually overestimate the likelihood of becoming infected, ${ }^{34}$ which has been reported for COVID-19 13 and earthquakes. ${ }^{32}$

This study identifies the vulnerable regions where individuals are more likely to suffer from well-being issues and helps to guide medical professionals' attention toward the more mentally vulnerable groups based on the distance from the epicenter in the COVID-19 outbreak in Peru: Lima (the capital of Peru). The "ripple effect" refers to the phenomenon that the mental health issues are more problematic for people around the center of the epicenter, which was the case for mental health services during the SARS and Ebola outbreaks. ${ }^{35-37}$ However, because tremendous amount of social media exposure and information have been perceived during the COVID-19 outbreak, ${ }^{38}$ our research group already has reported that in China individuals' well-being deteriorates over distance from the epicenter, ${ }^{13}$ as depicted by the psychological typhoon eye theory. ${ }^{31,32}$ In this study, we test whether the typhoon eye theory works and for whom it works in the COVID-19 outbreak in Peru.

We performed our analysis on healthcare workers as they are a COVID-19 vulnerable group. We selected age as a variable because it has been reported that the younger population are usually more adaptive to a natural disaster or to the outbreak of a virus. ${ }^{39,40}$ However, younger population also tend to access information on COVID-19 more frequently via digital sources such as social media, ${ }^{41}$ which causes them to be exposed to more negative content. ${ }^{42}$ Family size is an indicator of social support that one could receive during crisis like the current one ${ }^{43}$ because it served as an important resource to buffer stress and anxiety. ${ }^{44}$ We surveyed healthcare workers in 15 of the 24 provinces in Peru; these locations vary in their travel distance from the epicenter of Lima $(0-1,292 \mathrm{~km})$. We used anxiety, distress, and turnover intention scales to assess the mental health of healthcare workers in Peru after 1 month of lockdown and social distancing measures. 
Turnover intention is defined as the likelihood of an employee to leave his current job. ${ }^{45}$ Overall, drawing from psychological typhoon eye,$^{31,32}$ this study provided a snapshot of adult healthcare workers' mental health during the ongoing COVID-19 pandemic to enable more targeted mental health support in Peru.

\section{METHODS}

Study design. We conducted a cross-sectional survey from April 10, 2020 to May 2, 2020, after 1 month of lockdown and social distancing measures, in Peru because of the COVID-19 outbreak. At the beginning of the survey (April 10), the number of confirmed cases in Peru was 5,897 and 169 deaths, ${ }^{46}$ whereas at the end of the survey (May 2), the number of cases increased to 42,534 and the number of deaths increased to $1,200 .{ }^{47}$ We surveyed healthcare workers from 15 Peruvian provinces with varying severities of COVID-19. Lima, the capital of Peru, was considered the epicenter of the COVID-19 outbreak because the first case of COVID-19 in Peru appeared in Lima. It also continuously reported the highest number of COVID-19 patients during the survey, with 4,210 cases (71.4\% of total cases) on April $10^{46}$ and with 26,908 cases (63.3\% of total cases) on May $2 .{ }^{47}$

Participants. The online survey reached 400 healthcare workers in healthcare organizations such as hospitals, clinics, first emergency responders, medical wards, nursing home, dental clinics, pharmacies, and other healthcare institutions. We received responses from 303 of them (response rate of 75\%), who worked in 111 healthcare facilities, including 55 healthcare facilities in Lima, 33 healthcare facilities in Loreto, and 23 healthcare facilities from the other 22 cities (at least one from each city). Their distance to the epicenter (Lima) ranged from $0 \mathrm{~km}$ to $1,292 \mathrm{~km}$. All survey participants provided their informed consent before the enrollment. The survey was approved by the Tsinghua University Ethics Committee (\#20200322). The participants remained anonymous and had the option to finish the survey at any time, and their information was kept confidential. The participants were not involved in any of the planning, execution, and reporting stages of the study.

Outcomes and covariates. Healthcare workers' anxiety, distress, and turnover intention were assessed using the seven-item Generalized Anxiety Disorder (GAD-7) scale, ${ }^{48}$ the Kessler Psychological Distress scale (K6), ${ }^{49}$ and the two-item turnover intention scale, ${ }^{50}$ respectively. The total score of anxiety was considered as normal (0-4), mild (5-9), moderate (10-14), and severe (15-21), whereas the psychological distress was considered as low $(<5)$, moderate (5-12), and serious $(\geq 13)$. The cutoff value to consider the presence of anxiety was $10^{51}$ and 13 for psychological distress. ${ }^{52}$

The healthcare workers reported their age, gender, family status, education, occupation, type of healthcare organization (public or private), job level (entry, junior, intermediate, senior, and chief), exercise hours per day in the past week, and chronic health issues (yes or no). Education included the categories of high school, technical, bachelors, medical specialty, masters, and doctorate. Participants reported whether they had any chronic disease because comorbidities increase the chance of complications in a person with COVID- $19^{53}$ and because people with ongoing medical issues could be more anxious. Using their work locations, we calculated the distance of their cities to the epicenter of Lima for each participant.

Statistical analysis. Data analysis was performed in STATA version 16.0 (StataCorp LLC, College Station, TX) with a significance level set at $P<0.05$, and all tests were two-tailed. We used linear regression to predict anxiety, distress, and turnover intention using unweighted data.

\section{RESULTS}

Table 1 presents the descriptive characteristics of the participating healthcare workers. Of the 303 healthcare workers, $53(17 \%)$ were physicians, $63(21 \%)$ were nurses, $63(21 \%)$ were pharmacists, $80(26 \%)$ were technicians, 20 (7\%) were volunteers, and 24 (8\%) were others. Most participants were female (194 [64\%]), aged 25-44 years (229 [76\%]), single without any children (107 [35\%]) or married with more than one child (75 [25\%]), had bachelor degrees or higher (235 [78\%]), and worked full time (210 [69\%]) in public healthcare institutions (213 [70\%]). The average distance of the participants to the epicenter of Lima was $424 \mathrm{~km}$, with a SD of $490 \mathrm{~km}$. The participants scored an average of 15.4 (SD of 4.6) in the GAD-7 anxiety scale, and the average surpassed the cutoff of severe anxiety at $15 .^{51}$ In the $\mathrm{K} 6$ distress scale, the participants scored an average of 19.2 (SD of 4.5), higher than the cutoff of mental distress disorder at $13 .{ }^{52}$

Predictors of anxiety, distress, and turnover intention. The regression results in Table 2 examined the predictors of anxiety, mental distress, and turnover intention of healthcare workers in Peru during the COVID-19 outbreak. Education level had a negative association with anxiety $(\beta=-0.746, \mathrm{Cl}$ : -1.441 to $-0.050, P=0.036)$. The effects of gender, age, work level, type of contract, and type of institution on anxiety were not significant. In the case of mental distress, the predictors (gender, age, education level, work level, type of contract, or type of institution) were not significant. There was a negative association between age and turnover $(\beta=-0.033, \mathrm{Cl}:-0.057$ to $-0.008, P=0.009)$, with younger healthcare workers $(\beta=$ $2.817, \mathrm{Cl}: 2.452$ to 3.181 ) aged among $18-24$ years in comparison to $35-44$ years ( $\beta=2.162, C l$ : 1.946 to 2.378 ). Healthcare workers in the private sector had a higher turnover intention than those in the public sector $(\beta=-0.420, \mathrm{Cl}:-0.810$ to $-0.031, P=0.035)$. The effects of gender, education level, and work level on turnover intention were not significant.

The distance to the epicenter as a predictor. First, margin analysis revealed the relationship between the distance to the epicenter and anxiety was significantly negative, a ripple effect, taking all the other covariates equal $(\beta=-0.002, \mathrm{Cl}$ : -0.004 to $-0.0002, P=0.031)$. This relationship, however, might vary when other variables changed. The regression results in Table 2 indicated a significant interaction effect between the distance to the epicenter and the type of institution on anxiety $(\beta=-0.005, \mathrm{Cl}:-0.010$ to $-0.000, P=0.049)$. The interaction effect between the distance to the epicenter and job contract (full time versus part time) on anxiety was not significant ( $\beta=0.002$, $\mathrm{Cl}:-0.001$ to $0.005, P=0.223$ ). Yet, margin analysis showed the relationship between the distance to the epicenter and anxiety was significant and showed a ripple effect only among full-time healthcare workers ( $\beta=-0.003, \mathrm{Cl}:-0.005$ to $-0.001, P=0.011)$ and not among temporary healthcare workers $(\beta=-0.001, \mathrm{Cl}$ : -0.004 to $0.002, P=0.583$ ). 
TABLE 1

Characteristics of responders

\begin{tabular}{|c|c|c|c|c|c|c|c|c|c|c|}
\hline \multirow[b]{3}{*}{ Characteristic } & \multirow[b]{3}{*}{ Total } & \multicolumn{8}{|c|}{ Count, $n(\%)$} & \\
\hline & & \multicolumn{6}{|c|}{ Occupation } & \multicolumn{3}{|c|}{ Location } \\
\hline & & Physician & Nurse & Pharmacist & Technician & Volunteer & Others ${ }^{\star}$ & Lima & Loreto & Other \\
\hline Overall & $303(100)$ & $53(17)$ & $63(21)$ & $63(21)$ & $80(26)$ & $20(7)$ & $24(8)$ & 158 (52) & $110(36)$ & $35(12)$ \\
\hline \multicolumn{11}{|l|}{ Gender } \\
\hline Men & $109(36)$ & $28(26)$ & $19(17)$ & $18(17)$ & $23(21)$ & $9(8)$ & $12(11)$ & $44(40)$ & $49(45)$ & 16 (15) \\
\hline Women & $194(64)$ & $25(13)$ & $44(23)$ & $45(23)$ & $57(29)$ & $11(6)$ & $12(6)$ & $114(59)$ & $61(31)$ & 19 (10) \\
\hline \multicolumn{11}{|l|}{ Age-group (years) } \\
\hline $18-24$ & $9(3)$ & $0(0)$ & $1(2)$ & $1(2)$ & 2 (3) & $2(10)$ & $3(13)$ & $1(1)$ & $6(5)$ & $2(6)$ \\
\hline $25-34$ & $93(31)$ & $11(21)$ & $13(21)$ & $14(22)$ & $40(50)$ & 7 (35) & $8(33)$ & 51 (32) & 32 (29) & $10(29)$ \\
\hline $35-44$ & $136(45)$ & $25(47)$ & $41(65)$ & $27(43)$ & $22(28)$ & $10(50)$ & $11(46)$ & 77 (49) & $47(43)$ & $12(34)$ \\
\hline $45-54$ & $52(17)$ & $13(25)$ & $6(10)$ & $18(29)$ & $14(18)$ & $1(5)$ & $0(0)$ & $23(15)$ & $20(18)$ & $9(26)$ \\
\hline$>55$ & $13(4)$ & $4(8)$ & $2(3)$ & 3 (5) & $2(3)$ & $0(0)$ & $2(8)$ & $6(4)$ & $5(5)$ & $2(6)$ \\
\hline \multicolumn{11}{|l|}{ Family status } \\
\hline Single without any children & $107(35)$ & $10(19)$ & $21(33)$ & $17(27)$ & $35(44)$ & $13(65)$ & $11(46)$ & $72(46)$ & $22(20)$ & $13(37)$ \\
\hline Single with one child & $24(8)$ & $4(8)$ & $2(3)$ & $3(5)$ & $7(9)$ & $6(30)$ & $2(8)$ & $6(4)$ & $18(16)$ & $0(0)$ \\
\hline $\begin{array}{l}\text { Single with more than } \\
\text { one children }\end{array}$ & $4(1)$ & $3(6)$ & $0(0)$ & $1(2)$ & $0(0)$ & $0(0)$ & $0(0)$ & $2(1)$ & $0(0)$ & $2(6)$ \\
\hline Married without any children & $6(2)$ & $3(6)$ & $0(0)$ & $1(2)$ & $1(1)$ & $0(0)$ & $1(4)$ & $4(3)$ & $1(1)$ & $1(3)$ \\
\hline Married with one child & $37(12)$ & $7(13)$ & $9(14)$ & $12(19)$ & $7(9)$ & $0(0)$ & $2(8)$ & $24(15)$ & $9(8)$ & $4(11)$ \\
\hline $\begin{array}{l}\text { Married with more than } \\
\text { one children }\end{array}$ & $75(25)$ & $16(30)$ & $20(32)$ & $18(29)$ & $18(23)$ & $0(0)$ & $3(13)$ & $38(24)$ & $28(25)$ & $9(26)$ \\
\hline Divorced or others & $50(17)$ & $10(19)$ & $11(17)$ & $11(17)$ & $12(15)$ & $1(5)$ & $5(21)$ & $12(8)$ & $32(29)$ & $6(17)$ \\
\hline \multicolumn{11}{|l|}{ Number of children } \\
\hline 0 & 119 (39) & $15(28)$ & $21(33)$ & $22(35)$ & $36(45)$ & $13(65)$ & $12(50)$ & $81(51)$ & $23(21)$ & $15(43)$ \\
\hline 1 & $80(26)$ & $15(28)$ & $16(25)$ & $18(29)$ & $16(20)$ & $7(35)$ & $8(33)$ & 34 (22) & $40(36)$ & $6(17)$ \\
\hline 2 & 59 (19) & $11(21)$ & $11(17)$ & $21(33)$ & $13(16)$ & $0(0)$ & $3(13)$ & $28(18)$ & $22(20)$ & 9 (26) \\
\hline 3 & $31(10)$ & $6(11)$ & $10(16)$ & $2(3)$ & $12(15)$ & $0(0)$ & $1(4)$ & $8(5)$ & $18(16)$ & $5(14)$ \\
\hline 4 & $10(3)$ & $4(8)$ & $4(6)$ & $0(0)$ & $2(3)$ & $0(0)$ & $0(0)$ & $6(4)$ & $4(4)$ & $0(0)$ \\
\hline$>4$ & $4(1)$ & $2(4)$ & $1(2)$ & $0(0)$ & $1(1)$ & $0(0)$ & $0(0)$ & $1(1)$ & $3(3)$ & $0(0)$ \\
\hline \multicolumn{11}{|l|}{ Education level } \\
\hline High school & $1(0)$ & $0(0)$ & $0(0)$ & $0(0)$ & $1(1)$ & $0(0)$ & $0(0)$ & $0(0)$ & $0(1)$ & $0(0)$ \\
\hline Technical & $67(22)$ & $2(4)$ & $3(5)$ & $1(2)$ & $41(64)$ & 1 (5) & $9(38)$ & $25(16)$ & $40(36)$ & $2(6)$ \\
\hline Bachelors & $148(49)$ & $16(30)$ & $42(67)$ & $32(51)$ & $28(35)$ & 19 (95) & $11(46)$ & $87(55)$ & $47(43)$ & $14(40)$ \\
\hline Specialty & $33(11)$ & $24(45)$ & $5(8)$ & $3(5)$ & $0(0)$ & $0(0)$ & $1(4)$ & $19(12)$ & $10(9)$ & $4(11)$ \\
\hline Masters & $52(17)$ & $11(21)$ & $13(21)$ & $25(40)$ & $0(0)$ & $0(0)$ & $3(13)$ & $27(17)$ & $12(11)$ & $13(37)$ \\
\hline Doctorate & $2(1)$ & $0(0)$ & $0(0)$ & $2(3)$ & $0(0)$ & $0(0)$ & $0(0)$ & $0(0)$ & $0(0)$ & $2(6)$ \\
\hline \multicolumn{11}{|l|}{ Work level } \\
\hline New & $37(12)$ & $5(9)$ & $0(0)$ & $4(6)$ & $4(5)$ & $20(100)$ & $4(17)$ & $11(7)$ & $25(23)$ & 37 (12) \\
\hline Junior & $26(9)$ & $3(6)$ & $1(2)$ & $4(6)$ & $15(19)$ & $0(0)$ & $3(13)$ & $20(13)$ & $3(3)$ & $26(9)$ \\
\hline Intermediate & $190(63)$ & $30(57)$ & $58(92)$ & $29(46)$ & $61(76)$ & $0(0)$ & $12(50)$ & $101(64)$ & 70 (64) & $190(63)$ \\
\hline Senior & $21(7)$ & $5(9)$ & $1(2)$ & $12(19)$ & $0(0)$ & $0(0)$ & $3(13)$ & $15(9)$ & $3(3)$ & $21(7)$ \\
\hline Chief & $29(10)$ & 10 (19) & $3(5)$ & $14(22)$ & $0(0)$ & $0(0)$ & $2(8)$ & $11(7)$ & $9(8)$ & $29(10)$ \\
\hline \multicolumn{11}{|l|}{ Type of contract } \\
\hline Part time & $93(31)$ & $10(19)$ & $18(29)$ & $12(19)$ & $50(63)$ & $0(0)$ & $3(13)$ & $54(34)$ & 35 (32) & $4(11)$ \\
\hline Full time & $210(69)$ & $42(81)$ & $45(71)$ & $51(81)$ & $30(38)$ & $20(100)$ & $21(88)$ & $104(66)$ & $75(68)$ & $31(89)$ \\
\hline \multicolumn{11}{|l|}{ Type of institution } \\
\hline Public & $213(70)$ & 37 (59) & $50(79)$ & $50(79)$ & $40(50)$ & 19 (95) & $18(75)$ & $74(47)$ & $107(97)$ & $32(91)$ \\
\hline Private & $90(30)$ & $26(41)$ & $13(21)$ & $13(21)$ & $40(50)$ & $1(5)$ & $6(25)$ & $84(53)$ & $3(3)$ & $3(9)$ \\
\hline \multicolumn{11}{|l|}{ City } \\
\hline Lima & $158(52)$ & $23(43)$ & $38(60)$ & $38(60)$ & $47(59)$ & $0(0)$ & $12(50)$ & NA & NA & NA \\
\hline Loreto & $110(36)$ & $23(43)$ & $19(30)$ & $6(10)$ & $31(39)$ & $20(100)$ & $11(46)$ & NA & NA & NA \\
\hline Other & $35(12)$ & $7(13)$ & $6(10)$ & $19(30)$ & $2(3)$ & $0(0)$ & $1(4)$ & NA & NA & NA \\
\hline \multicolumn{11}{|l|}{ Distance to the epicenter $(\mathrm{km})$} \\
\hline 0 & $165(54)$ & $24(45)$ & $41(65)$ & $41(65)$ & $47(59)$ & $0(0)$ & $12(50)$ & $158(100)$ & $0(0)$ & $7(20)$ \\
\hline $1-300$ & $7(2)$ & $2(4)$ & $0(0)$ & $4(6)$ & 1 (1) & $0(0)$ & $0(0)$ & $0(0)$ & $0(0)$ & 7 (20) \\
\hline $301-600$ & 7 (2) & $2(4)$ & $0(0)$ & $4(6)$ & $1(1)$ & $0(0)$ & $0(0)$ & $0(0)$ & $0(0)$ & 7 (20) \\
\hline $601-900$ & 7 (2) & $1(2)$ & $3(5)$ & $2(3)$ & $0(0)$ & $0(0)$ & $1(4)$ & $0(0)$ & $0(0)$ & 7 (20) \\
\hline $901-1,200$ & $116(38)$ & 24 (45) & $19(30)$ & $11(17)$ & 31 (39) & $20(100)$ & $11(46)$ & $0(0)$ & $110(100)$ & $6(17)$ \\
\hline$>1,200$ & $1(0)$ & $0(0)$ & $0(0)$ & $1(2)$ & $0(0)$ & $0(0)$ & $0(0)$ & $0(0)$ & $0(0)$ & 1 (3) \\
\hline
\end{tabular}

Second, margin analysis revealed the relationship between the distance to the epicenter and anxiety was significantly negative, a ripple effect, taking all the other covariates equal ( $\beta=-0.003, \mathrm{Cl}:-0.005$ to $-0.004, P=0.023$ ). This relationship, also, varied when other variables changed. The regression results in Table 2 indicated a significant interaction effect between the distance to the epicenter and the type of institution on anxiety $(\beta=-0.008, \mathrm{Cl}:-0.014$ to $-0.002, P=$ 0.010). Margin analysis showed the relationship between the distance to the epicenter and anxiety was significant and 
TABLE 2

OLS regression results on the GAD-7 scale, $\mathrm{K} 6$ scale, and turnover intention of health workers by gender, age, number of children, education level, work level, type of contract, type of institution, and distance to the epicenter

\begin{tabular}{|c|c|c|c|c|}
\hline \multirow[b]{2}{*}{ Variable } & \multirow[b]{2}{*}{ Count, $n(\%)$} & \multicolumn{3}{|c|}{ Parameter estimates $(95 \% \mathrm{Cl})$} \\
\hline & & GAD-7 scale & K6 scale & Turnover intention \\
\hline Gender & $303(100)$ & $0.734(-0.472$ to 1.939$)$ & $0.350(-1.119$ to 1.819$)$ & $-0.098(-0.431$ to 0.235$)$ \\
\hline Age-group (years) & $303(100)$ & $-0.008(-0.097$ to 0.081$)$ & $-0.011(-0.119$ to 0.097$)$ & $-0.033^{\star}(-0.057$ to -0.008$)$ \\
\hline $18-24$ & $9(3)$ & 6.989 (5.670 to 8.307$)$ & 10.157 (8.551 to 11.764$)$ & 2.817 (2.452 to 3.1819$)$ \\
\hline $25-34$ & $93(31)$ & 6.906 (6.284 to 7.528$)$ & 10.045 (9.287 to 10.803$)$ & 2.489 (2.317 to 2.661$)$ \\
\hline $35-44$ & $136(45)$ & 6.824 (6.043 to 7.605$)$ & 9.933 (8.981 to 10.885$)$ & 2.162 (1.946 to 2.378$)$ \\
\hline $45-54$ & $52(17)$ & 6.742 (5.190 to 8.294$)$ & 9.821 (7.929 to 11.712$)$ & 0.834 (1.406 to 2.263$)$ \\
\hline$>55$ & $13(4)$ & 6.660 (4.255 to 9.064$)$ & 9.709 (6.778 to 12.639$)$ & 1.507 (0.843 to 2.171$)$ \\
\hline Number of children & $303(100)$ & $0.035(-0.540$ to 0.611$)$ & $-0.061(-0.763$ to 0.640$)$ & $0.069(-0.090$ to 0.228$)$ \\
\hline Education level & 303 (100) & $-0.746 \dagger(-1.441$ to -0.050$)$ & $-0.322(-1.170$ to 0.526$)$ & $0.008(-0.184$ to 0.201$)$ \\
\hline Technician & $67(22)$ & $7.894(6.805$ to 8.984$)$ & 10.444 (9.117 to 11.772$)$ & 2.360 (2.060 to 2.661$)$ \\
\hline Bachelors & $148(49)$ & 7.149 (6.557 to 7.740$)$ & $10.122(9.401$ to 10.843$)$ & 2.369 (2.205 to 2.532$)$ \\
\hline Masters & $52(17)$ & 6.403 (5.709 to 7.097$)$ & 9.800 (8.955 to 10.646$)$ & 2.377 (2.186 to 2.569$)$ \\
\hline Doctorate & $2(1)$ & 5.657 (4.400 to 6.914$)$ & 9.478 (7.947 to 11.010$)$ & 2.386 (2.038 to 2.733$)$ \\
\hline Work level & $303(100)$ & 0.305 ( -0.348 to 0.959$)$ & $0.458(-0.339$ to 1.254$)$ & $-0.109(-0.289$ to 0.072$)$ \\
\hline Type of contract & 303 (100) & $0.230(-1.202$ to 1.662$)$ & $-0.354(-2.099$ to 1.391$)$ & $-0.078(-0.473$ to 0.318$)$ \\
\hline Part time & $93(31)$ & $-0.003 \ddagger(-0.005$ to -0.001$)$ & $-0.004 \S(-0.007$ to -0.002$)$ & $0.000(-0.000$ to 0.001$)$ \\
\hline Full time & $210(69)$ & $-0.001(-0.004$ to 0.002$)$ & $0.000(-0.004$ to 0.004$)$ & $0.000(-0.001$ to 0.001$)$ \\
\hline Type of institution & $303(100)$ & $0.633(-0.778$ to 2.044$)$ & $0.412(-1.307$ to 2.131$)$ & $-0.420^{\|}(-0.810$ to -0.031$)$ \\
\hline Public & $213(70)$ & $0.004(-0.001$ to 0.010$)$ & 0.008 (0.001 to 0.015$)$ & -0.003 ( $(-0.005$ to -0.002$)$ \\
\hline Private & $90(30)$ & $-0.000(-0.002$ to 0.001$)$ & $0.000(-0.002$ to 0.002$)$ & $-0.001^{\top}(-0.001$ to -0.000$)$ \\
\hline Distance to the epicenter $(\mathrm{km})$ & $303(100)$ & $0.004(-0.002$ to 0.010$)$ & $0.007(-0.000$ to 0.014$)$ & $-0.003^{\top}(-0.005$ to -0.002$)$ \\
\hline 0 & $165(54)$ & $7.070(6.440$ to 7.701$)$ & 10.176 (9.407 to 10.945$)$ & 2.508 (2.334 to 2.682$)$ \\
\hline $1-300$ & $7(2)$ & 6.393 (5.671 to 7.115$)$ & 9.304 (8.424 to 10.184$)$ & 2.567 (2.368 to 2.767$)$ \\
\hline $301-600$ & $7(2)$ & 5.716 (4.532 to 6.900$)$ & $8.432(7.000$ to 9.874$)$ & 2.626 (2.299 to 2.953$)$ \\
\hline $601-900$ & $7(2)$ & 5.039 (3.296 to 6.781$)$ & 7.560 (5.437 to 9.683$)$ & 2.685 (2.204 to 3.166$)$ \\
\hline$>901$ & $117(39)$ & 4.362 (2.032 to 6.691$)$ & 6.688 (3.850 to 9.527$)$ & 2.744 (2.101 to 3.388$)$ \\
\hline \multicolumn{5}{|c|}{ Interaction effects of type of institution and type of contract } \\
\hline $\begin{array}{l}\text { Distance to the epicenter } \times \\
\text { type of institution }\end{array}$ & $303(100)$ & $-0.005^{\star \star}(-0.010$ to -0.000$)$ & $-0.008+\dagger(-0.014$ to -0.002$)$ & $0.002 \ddagger \ddagger(0.001$ to 0.004$)$ \\
\hline $\begin{array}{l}\text { Distance to the epicenter } \times \\
\text { type of contract }\end{array}$ & $303(100)$ & $0.002(-0.001$ to 0.005$)$ & $0.004 \S \S(0.000$ to 0.008$)$ & $0.000(-0.001$ to 0.001$)$ \\
\hline 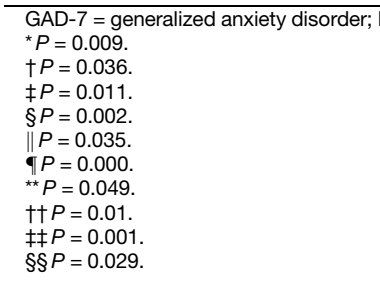 & psychological & ess; OLS = ordinary least squares. & & \\
\hline
\end{tabular}

showed a typhoon eye effect only among healthcare workers in public institutions ( $\beta=0.008, \mathrm{Cl}$ : 0.001 to $0.015, P=0.021$ ) and not among healthcare workers in private institutions $(\beta=$ $0.000, \mathrm{Cl}:-0.002$ to $0.002, P=0.883)$. The interaction effect between the distance to the epicenter and job contract (full time versus part time) on anxiety was also significant $(\beta=$ $0.004, \mathrm{Cl}: 0.000$ to $0.008, P=0.029$ ). Moreover, margin analysis showed the relationship between the distance to the epicenter and anxiety was significant and showed a ripple effect only among full-time healthcare workers $(\beta=-0.004, \mathrm{Cl}$ : -0.007 to $-0.002, P=0.002$ ) and not among temporary healthcare workers ( $\beta=0.001, \mathrm{Cl}:-0.004$ to $0.004, P=0.955$ ).

Third, margin analysis revealed the relationship between the distance to the epicenter and turnover was not significant taking all the other covariates equal $(\beta=0.002, \mathrm{Cl}: 0.0003$ to $0.001, P=0.494)$. The regression results in Table 2 indicated a significant interaction effect between the distance to the epicenter and the type of institution on turnover $(\beta=0.002$, Cl: 0.001 to $0.004, P=0.001)$. Margin analysis showed the relationship between the distance to the epicenter and turnover was significantly negative among healthcare workers in both public institutions $(\beta=-0.003, \mathrm{Cl}:-0.005$ to $-0.002, P=0.000)$ and private institutions $(\beta=-0.001, \mathrm{Cl}$ : -0.001 to $-0.000, P=0.000)$.

\section{DISCUSSION}

Since 2012, Peru implemented the community mental health model as recommended by the $\mathrm{WHO}^{54}$ as an approach to provide care in the community through specialized facilities called community mental health centers. However, as reported in 2019, actual full-time employees of these centers reported that there are critical barriers that still need to circumvent. ${ }^{55}$ Some of them include lack of consistent training, resources, structure, and policies that effectively support the use and importance of these centers in the evaluation and adequate treatment of mental health conditions. ${ }^{55}$

This situation also gets worsened when general practitioners in Peru consider themselves as not very competent in diagnosing and treating mental disorders. This was reported in a self-perception survey that evaluated the competence of Peruvian general practitioners in diagnosing and treating 
major depression, anxiety disorder, alcohol dependence, and schizophrenia. ${ }^{56}$ It is reported that of the 434 responders, $70.5 \%$ believed they were competent in diagnosing depression, $73.3 \%$ for anxiety, $67.6 \%$ for alcohol dependence, $62.0 \%$ for schizophrenia, and when the four mental disorders were combined, only $41.6 \%$ of participants self-perceived competence in providing an adequate diagnosis. ${ }^{56}$ These results highlighted the need to improve medical education so as to develop the skills necessary to confront mental health disorders. ${ }^{56}$ There is a very limited number of studies that have assessed mental health in the general public and healthcare workers in Peru, and, to the best of our knowledge, this study is the first to report the mental health of healthcare workers in Peru during the COVID-19 outbreak.

Our study shows that overall people who were geographically further from the epicenter in Peru during the outbreak experienced less anxiety and mental distress, corroborating the ripple effect and disconfirming the typhoon eye theory. ${ }^{11,13,31-33}$ However, this relationship can change depending on the type of institutions (public versus private) and contract (full time versus part time). The relationship between the distance to the epicenter and distress for healthcare workers in public institutions was positive, showing a typhoon eye effect $(\beta=0.008, \mathrm{Cl}: 0.001$ to $0.015, P=$ $0.021)$. Distance to the epicenter is a crucial factor for psychiatrists to consider to screen the mentally vulnerable groups, ${ }^{13,30,57}$ but research needs to first establish whether the distance to the epicenter carries a ripple effect or a typhoon eye effect. Furthermore, our results indicate that healthcare workers with a lower education level were more anxious, and younger healthcare workers and those in the private sector were more susceptible to turnover.

An important factor to consider is that at the beginning of the survey (April 10), the number of confirmed cases in Peru was 5,897 with 169 deaths, ${ }^{46}$ whereas at the end of the survey (May 2 ), the number of cases increased to 42,534 and the number of deaths increased to $1,200 .^{47}$ This significant increase in confirmed cases and the accompanying coverage in the national and international media could have also caused increased anxiety and distress in healthcare workers. In addition, the reported precarious health system and saturation of every hospital in Peru with COVID-19 patients ${ }^{3}$ could have also caused an increase in turnover intention for healthcare workers. Similar to Iran, ${ }^{17}$ China, ${ }^{13}$ and the United States, ${ }^{58}$ we did not identify a universal risk factor that could predict specific mental disorders in Peruvian healthcare workers. This is expected as each country has their own medical system, clinical capacity, access to PPE, labor conditions, lockdown policies, and cultures.

Limitations. The context of this study has a clear epicenter of COVID-19, Lima, in Peru. However, it is not always the case as observed in South Korea. ${ }^{59}$ Our data were collected in Peru, a geographically large country, and it remains unclear whether the typhoon eye effect or the ripple effect will generalize in other countries, most of which are smaller. The epicenter of Lima is in the midwest of Peru, whereas the epicenter of Wuhan is in the middle of China, and the epicenter of New York State in the United States is in the northeast. Thus, we suspect that either the typhoon eye effect or the ripple effect might play out differently in term of pace and patterns.

\section{CONCLUSION}

Our results show that Peru's healthcare workers' anxiety and mental distress decreased as the distance from the epicenter increases, corroborating the ripple effect and disconfirming the typhoon eye theory. A lower education level increased the anxiety levels, whereas age and gender did not affect the anxiety and distress levels. The turnover intention was not associated with the distance to the epicenter nor gender, but it was higher in younger healthcare workers in the private section. Our results can help guide mental health service providers toward vulnerable groups of healthcare workers that are closer to Lima, the COVID-19 epicenter in Peru. We urge for more research to assess the mental health of healthcare workers and general public in Peru, a country that was not given the importance it deserves.

Received July 3, 2020. Accepted for publication August 9, 2020.

Published online August 18, 2020.

Acknowledgments: We thank all the participants who contributed to our work. We acknowledge the support of Tsinghua UniversityINDITEX Sustainable Development Fund (Project no. TISD201904). Publication charges for this article were waived due to the ongoing pandemic of COVID-19.

Disclosure: Critical revision of the manuscript for important intellectual content was performed by J.A.Y., A.A.J. and S.X.Z.; statistical analysis was performed by S.X.Z.; J.L. obtained funding; administrative, technical, or material support was provided by A.A.J and A.A.R; and J.A.Y. and S.X.Z. performed supervision.

Authors' addresses: Jaime A. Yáñez, Carrera de Educacion y Gestion del Aprendizaje, Facultad de Educacion, Universidad Peruana de Ciencias Aplicadas, Lima, Peru, E-mail: jaimeayanez@gmail.com. Asghar Afshar Jahanshahi, CENTRUM Católica Graduate Business School (CCGBS), Pontificia Universidad Católica Del Peru (PUCP), Lima, Peru, E-mail: afshar@pucp.edu.pe. Aldo Alvarez-Risco, Carrera de Negocios Internacionales, Facultad de Ciencias Empresariales y Economicas, Universidad de Lima, Lima, Peru, E-mail: aralvare@ ulima.edu.pe. Jizhen Li, Tsinghua University, Beijing, China, E-mail: lijzh@sem.tsinghua.edu.cn. Stephen X. Zhang, University of Adelaide, Adelaide, Australia, E-mail: stephen.x.zhang@gmail.com.

This is an open-access article distributed under the terms of the Creative Commons Attribution (CC-BY) License, which permits unrestricted use, distribution, and reproduction in any medium, provided the original author and source are credited.

\section{REFERENCES}

1. Alvarez-Risco A et al., 2020. The Peru approach against the COVID-19 infodemic: insights and strategies. Am J Trop Med Hyg 103: 583-586.

2. Yáñez JA, Alvarez-Risco A, Delgado-Zegarra J, 2020. Rapid Response: Clearing the Path for COVID-19 in Peru? The Decision of Supervised Walks for Children and Adolescents. Available at: https:// www.bmj.com/content/369/bmj.m1918/r-9. Accessed June 3, 2020.

3. Yáñez JA, Alvarez-Risco A, Delgado-Zegarra J, 2020. COVID-19 in Peru: from supervised walks for children to the first case of Kawasaki-like syndrome. BMJ 369: m2418.

4. Yáñez JA, Alvarez-Risco A, Delgado-Zegarra J, 2020. Rapid Response: Does Peru Really Have That High Number of COVID-19 Confirmed Cases? The Deception of Combining RT-PCR and Rapid Test Results. Available at: https://www.bmj.com/content/ 369/bmj.m2518/rr-4. Accessed July 1, 2020.

5. MINSA, 2020. Alerta Epidemiológica AE-013-2020. Available at: https://www.dge.gob.pe/portal/docs/alertas/2020/AE013.pdf. Accessed May 26, 2020.

6. MINEDU, 2020. Minedu Suspende Clases en Universidades Públicas y Privadas para Evitar Propagación del Coronavirus. Available at: https://www.gob.pe/institucion/minedu/noticias/ 108801-minedu-suspende-clases-en-universidades-publicasy-privadas-para-evitar-propagacion-del-coronavirus. Accessed March 23, 2020 
7. PCM, 2020. Decreto Supremo $N^{\circ}$ 044-2020-PCM - Estado de Emergencia Nacional por las Graves Circunstancias que Afectan la vida de la Nación a consecuencia del brote del COVID-19. Gobierno del Peru: Presidencia del Consejo de Ministros.

8. Lima CKT, Carvalho PMdM, Lima IdAAS, Nunes JVAdO, Saraiva JS, de Souza RI, da Silva CGL, Neto MLR, 2020. The emotional impact of coronavirus 2019-nCoV (new coronavirus disease). Psychiatry Res 287: 112915.

9. Cao W, Fang Z, Hou G, Han M, Xu X, Dong J, Zheng J, 2020. The psychological impact of the COVID-19 epidemic on college students in China. Psychiatry Res 287: 112934.

10. Qiu J, Shen B, Zhao M, Wang Z, Xie B, Xu Y, 2020. A nationwide survey of psychological distress among Chinese people in the COVID-19 epidemic: implications and policy recommendations. Gen Psychiatr 33: e100213.

11. Zhang SX, Wang Y, Rauch A, Wei F, 2020. Unprecedented disruption of lives and work: health, distress and life satisfaction of working adults in China one month into the COVID-19 outbreak. Psychiatry Res 288: 112958.

12. Zhang SX, Liu J, Afshar Jahanshahi A, Nawaser K, Yousefi A, Li J, Sun S, 2020. At the height of the storm: healthcare staff's health conditions and job satisfaction and their associated predictors during the epidemic peak of COVID-19. Brain Behav Immun 87: 144-146.

13. Tang PM, Zhang SX, Li CH, Wei F, 2020. Geographical identification of the vulnerable groups during COVID-19 crisis: the typhoon eye effect and its boundary conditions. Psychiatry Clin Neurosci (Epub ahead of print 17 July 2020).

14. Lai J et al., 2020. Factors associated with mental health outcomes among health care workers exposed to coronavirus disease 2019. JAMA Netw Open 3: e203976.

15. Kang L et al., 2020. Impact on mental health and perceptions of psychological care among medical and nursing staff in Wuhan during the 2019 novel coronavirus disease outbreak: a crosssectional study. Brain Behav Immun 87: 11-17.

16. Tan BYQ et al., 2020. Psychological impact of the COVID-19 pandemic on health care workers in Singapore. Ann Intern Med Apr 6: M20-1083.

17. Jahanshahi AA, Dinani MM, Madavani AN, Li J, Zhang SX, 2020. The distress of Iranian adults during the COVID-19 pandemic more distressed than the Chinese and with different predictors. Brain Behav Immun 87: 124-125.

18. Moccia $L$ et al., 2020. Affective temperament, attachment style, and the psychological impact of the COVID-19 outbreak: an early report on the Italian general population. Brain Behav Immun 87: 75-79.

19. Mazza C, Ricci E, Biondi S, Colasanti M, Ferracuti S, Napoli C, Roma P, 2020. A nationwide survey of psychological distress among Italian people during the COVID-19 pandemic: immediate psychological responses and associated factors. Int $J$ Environ Res Public Health 17: 3165.

20. Maher $A$ et al., 2020. COVID-19 outbreak situation and its psychological impact among surgeon in training in France. World $J$ Urol Apr 24: 1-2.

21. Bacon AM, Corr PJ, 2020. Coronavirus (COVID-19) in the United Kingdom: a personality-based perspective on concerns and intention to self-isolate. $\mathrm{Br} J$ Health Psychol (Epub ahead of print 29 April 2020).

22. Ozamiz-Etxebarria N, Dosil-Santamaria M, Picaza-Gorrochategui M, Idoiaga-Mondragon N, 2020. Stress, anxiety, and depression levels in the initial stage of the COVID-19 outbreak in a population sample in the northern Spain. Cad Saude Publica 36: e00054020.

23. Gonzalez-Sanguino C, Ausin B, AngelCastellanos M, Saiz J, Lopez-Gomez A, Ugidos C, Munoz M, 2020. Mental health consequences during the initial stage of the 2020 coronavirus pandemic (COVID-19) in Spain. Brain Behav Immun 87: 172-176.

24. Lagasse J, 2020. Healthcare Workers Risk Burnout, Exposure in Wake of Coronavirus Pandemic. Available at: https://www. healthcarefinancenews.com/news/healthcare-workers-riskburnout-exposure-wake-coronavirus-pandemic. Accessed May $15,2020$.

25. Langer G, 2020. Coronavirus Impacts: Disrupted Lives, Elevated Stress, and Soaring Worry. Available at: https://abcnews.go.com/
Politics/coronavirus-impacts-disrupted-lives-elevated-stresssoaring-worry/story?id=69812058. Accessed May 15, 2020.

26. Xiang Y-T, Yang Y, Li W, Zhang L, Zhang Q, Cheung T, Ng CH, 2020. Timely mental health care for the 2019 novel coronavirus outbreak is urgently needed. Lancet Psychiatry 7: 228-229.

27. Duan L, Zhu G, 2020. Psychological interventions for people affected by the COVID-19 epidemic. Lancet Psychiatry 7: 300-302.

28. Brooks S, Webster R, Smith L, Woodland L, Wessely S, Greenberg N, Rubin G, 2020. The psychological impact of quarantine and how to reduce it: rapid review of the evidence. Lancet 395: P912-P920.

29. Lombardo P, Jones W, Wang L, Shen X, Goldner EM, 2018. The fundamental association between mental health and life satisfaction: results from successive waves of a Canadian national survey. BMC Public Health 18: 342.

30. Koivumaa-Honkanen H, Kaprio J, Honkanen RJ, Viinamaki H, Koskenvuo M, 2005. The stability of life satisfaction in a 15-year follow-up of adult Finns healthy at baseline. BMC Psychiatry 5: 4.

31. Xie X-F, Stone E, Zheng R, Zhang R-G, 2011. The 'typhoon eye effect': determinants of distress during the SARS epidemic. J Risk Res 14: 1091-1107.

32. Li S, Rao L-L, Ren X-P, Bai X-W, Zheng R, Li J-Z, Wang Z-J, Liu H, 2009. Psychological typhoon eye in the 2008 Wenchuan earthquake. PLoS One 4: e4964.

33. Zhang SX, Huang H, Wei F, 2020. Geographical distance to the epicenter of COVID-19 predicts the burnout of the working population: ripple effect or typhoon eye effect? Psychiatry Res 288: 112998.

34. Halpern-Felsher BL, Millstein SG, Ellen JM, Adler NE, Tschann $\mathrm{JM}$, Biehl M, 2001. The role of behavioral experience in judging risks. Health Psychol 20: 120-126.

35. Slovic P, 1987. Perception of risk. Science 236: 280-285.

36. Des Jarlais DC, Galea S, Tracy M, Tross S, Vlahov D, 2006. Stigmatization of newly emerging infectious diseases: AIDS and SARS. Am J Public Health 96: 561-567.

37. Kinsman J, 2012. "A time of fear": local, national, and international responses to a large Ebola outbreak in Uganda. Global Health 8: 15.

38. Gao J, Zheng P, Jia Y, Chen H, Mao Y, Chen S, Wang Y, Fu H, Dai $\mathrm{J}, 2020$. Mental health problems and social media exposure during COVID-19 outbreak. PLoS One 15: e0231924.

39. Rafiey H, Momtaz YA, Alipour F, Khankeh H, Ahmadi S, Sabzi Khoshnami M, Haron SA, 2016. Are older people more vulnerable to long-term impacts of disasters? Clin Interv Aging 11: 1791-1795.

40. Lau AL, Chi I, Cummins RA, Lee TM, Chou KL, Chung LW, 2008. The SARS (severe acute respiratory syndrome) pandemic in Hong Kong: effects on the subjective wellbeing of elderly and younger people. Aging Ment Health 12: 746-760.

41. Greenwood S, Perrin A, Duggan M, 2016. Social Media Update 2016: Facebook Usage and Engagement Is on the Rise, while Adoption of Other Formats Holds Steady. Available at: https:// www.pewresearch.org/internet/2016/11/11/social-media-update2016/. Accessed June 24, 2020.

42. Kessler RC, Downey G, Milavsky JR, Stipp H, 1988. Clustering of teenage suicides after television news stories about suicides: a reconsideration. Am J Psychiatry 145: 1379-1383.

43. Aptekar L, Boore J, 1990. The emotional effects of disaster on children: a review of the literature. Int $J$ Ment Health 19: 77-90.

44. Novilla ML, Barnes MD, De La Cruz NG, Williams PN, Rogers J, 2006. Public health perspectives on the family: an ecological approach to promoting health in the family and community. Fam Community Health 29: 28-42.

45. Belete $A, 2018$. Turnover intention influencing factors of employees: an empirical work review. Int J Res Bus Stud Manag 5: 23-31.

46. MINSA, 2020. Minsa: Casos Confirmados por Coronavirus COVID-19 Ascienden a 5897 en el Perú (Comunicado $N^{\circ}$ 61). Available at: https://www.gob.pe/institucion/minsa/noticias/ 112148-minsa-casos-confirmados-por-coronavirus-covid-19ascienden-a-5-897-en-el-peru-comunicado-n-61. Accessed June 24, 2020.

47. MINSA, 2020. Minsa: Casos Confirmados por Coronavirus COVID-19 Ascienden a 42534 (Comunicado $N^{\circ}$ 85). Available at: https://www.gob.pe/institucion/minsa/noticias/143615- 
minsa-casos-confirmados-por-coronavirus-covid-19-asciendena-42-534-comunicado-n-85. Accessed June 24, 2020.

48. He XY, Li C, Qian J, Cui HS, Wu WY, 2010. Reliability and validity of a generalized anxiety scale in general hospital outpatients. Shanghai Arch Psychiatry 22: 200-203.

49. Kessler RC et al., 2003. Screening for serious mental illness in the general population. Arch Gen Psychiatry 60: 184-189.

50. Metcalf AY, Stoller JK, Habermann M, Fry TD, 2015. Respiratory therapist job perceptions: the impact of protocol use. Respir Care 60: 1556-1559.

51. Tong X, An D, McGonigal A, Park S-P, Zhou D, 2016. Validation of the generalized anxiety disorder-7 (GAD-7) among Chinese people with epilepsy. Epilepsy Res 120: 31-36.

52. Prochaska JJ, Sung H-Y, Max W, Shi Y, Ong M, 2012. Validity study of the K6 scale as a measure of moderate mental distress based on mental health treatment need and utilization. Int $J$ Methods Psychiatr Res 21: 88-97.

53. Gates B, 2020. Responding to COVID-19-a once-in-a-century pandemic? N Engl J Med 382: 1677-1679.

54. Funk M, Saraceno B, Pathare S, 2003. Organization of Services for Mental Health. Available at: https://www.who.int/mental_ health/policy/services/4_organisation\%20services_WEB_07. pdf?ua=1. Accessed June 14, 2020.
55. Arriola-Vigo JA, Stovall JG, Moon TD, Audet CM, Diez-Canseco F, 2019. Perceptions of community involvement in the Peruvian mental health reform process among clinicians and policymakers: a qualitative study. Int $J$ Health Policy Manag 8: 711-722.

56. Zafra-Tanaka JH, Pacheco-Barrios K, Inga-Berrospi F, TaypeRondan A, 2019. Self-perceived competencies in the diagnosis and treatment of mental health disorders among general practitioners in Lima, Peru. BMC Med Educ 19: 464.

57. Rissanen T, Viinamäki H, Lehto SM, Hintikka J, Honkalampi K, Saharinen T, Koivumaa-Honkanen H, 2013. The role of mental health, personality disorders and childhood adversities in relation to life satisfaction in a sample of general population. Nord J Psychiatry 67: 109-115.

58. Brody DJ, Pratt LA, Hughes JP, 2018. Prevalence of depression among adults aged 20 and over: united states, 2013-2016. NCHS Data Brief 303: 1-8.

59. Chang-kyong P, 2020. Coronavirus Cluster Emerges at Another South Korean Church, as Others Press Ahead with Sunday Services. Available at: https://www.scmp.com/ week-asia/health-environment/article/3077497/coronaviruscluster-emerges-another-south-korean. Accessed May 24, 2020. 